\title{
More is not Always Better: An Epidemiological Assessment of Migraine Frequency and the Impact on Relationships
}

Amy Wachholtz ${ }^{1 *}$, Amrita Bhowmick ${ }^{2}$, LB Herbert ${ }^{2}$ and Dawn Marcus ${ }^{3}$

${ }^{1}$ Division of Addiction Psychiatry, Department of Psychiatry, University of Colorado Denver and University of Massachusetts Medical School, USA

${ }^{2}$ Health Union, LLC, Philadelphia, Pennsylvania, USA

${ }^{3}$ Department of Anesthesiology and Neurology, University of Pittsburg Medical Center, USA

\begin{abstract}
Objective: Chronic pain negatively impacts spouse/partner relationships, with greater impact associated with higher pain severity and co-morbid mood disturbance. This study investigated the role of pain episode frequency in migraineurs on relationship effects.
\end{abstract}

Methods: An online survey was conducted, collecting information about migraine, psychological distress, and relationship impact using standardized measures. Adults previously diagnosed with migraine were invited to participate through postings on migraine community websites and social media. Impact was evaluated based on four migraine frequency categories (migraines/month): less than weekly (0-3), one to two episodes weekly (4-9 and 10-15), and more than twice weekly $(>15)$.

Results: A total of 1,399 adult migraineurs were included. Spouse/partner relationships had been mildly-moderately damaged for $30 \%$ with $0-3$ migraine monthly, increasing to $40 \%$ with $>15$ migraine monthly. Migraine had contributed to a break-up for $4 \%$ with $0-3$ migraines monthly, increasing to $8 \%$ for those with $>15$ migraines monthly. About $57 \%$ of participants reported satisfaction with their current spouse/partner, with satisfaction unaffected by migraine frequency among those who were satisfied with their partners. Negative impact on relationships with children and close friends also increased with migraine frequency. Depression and anxiety were significantly correlated with migraine frequency $(P<0.001)$ and modulated relationship impact.

Conclusion: As migraine frequency increased, negative impact on relationships also increased. Interestingly, satisfaction with current spouse/partner was high for all migraine frequency categories. Clinically, this suggests that frequent migraineurs may benefit from a referral to couples counseling with a therapist that specializes in medically ill.

Keywords: Migraine; Headache; Relationship quality; Frequency

\section{Introduction}

Chronic pain may have a negative impact on significant relationships. A survey of marital relationship satisfaction in 58 chronic pain patients and their spouses reported dissatisfaction consistent with marital disturbance in 39\% [1]. Another survey investigating marital satisfaction in 139 couples in which one partner has chronic pain found a negative relationship between marital satisfaction and co-morbid anxiety and depression [2]. Catastrophizing was also linked with reduced marital satisfaction, while pain severity was not. A subsequent survey of 54 patients with chronic low back pain and their married or cohabitating partners linked greater depression, negative responses from a partner, and higher pain severity with reduced relationship satisfaction [3]. An analysis of 110 couples in which one partner has chronic pain linked psychosocial distress and pain severity in the patient with reduced marital satisfaction for the spouse [4]. A recent online survey of 6,126 adults with fibromyalgia rated satisfaction with current spouse or partner using the validated Relationship Assessment Scale [5]. Half of fibromyalgia participants (51\%) were not satisfied with their current spouse/partner relationship. Co-morbid depression and anxiety symptoms and higher fibromyalgia severity were linked with reduced relationship satisfaction. In general, studies show bidirectional relationships among martial satisfaction, psychological distress, and pain severity $[6,7]$.

The current study was designed to investigate the relationship between pain episode frequency and relationship satisfaction, evaluating migraine as the pain model. Migraine has also been shown to negatively impact important social relationships $[8,9]$. Because migraine is an episodic pain disorder with a range of frequencies across patients, this was selected as a model to study the potential role of pain episode frequency on relationship impact. This study was conducted by sampling online migraine communities. Web-based surveys are becoming more commonly used tools to help capture information about a wide range of health conditions [10], including migraine [11,12].

\section{Materials and Methods}

The survey was hosted from January 7, 2013 to March 6, 2013 by Migraine.com, a migraine-specific community website. A two-month time frame was selected for recruitment to permit sufficient time to make the survey available so that a broader sample might be selected through social media recruitment than a shorter duration survey. A two-month frame has been found in previous online surveys to obtain $>1,000$ participants, with survey participation typically decreasing substantially before two months are completed such that longer duration recruitment is not likely to substantially increase sample size $[5,13]$. Prior to initiation of this survey, this study was reviewed

*Corresponding author: Amy Wachholtz, Department of Psychiatry, Division of Addiction Psychiatry, University of Colorado Denver and University of Massachusetts Medical School, USA, Tel: 3033157051; E-mail: amy. wachholtz@ucdenver.edu

Received June 21, 2017; Accepted July 07, 2017; Published July 14, 2017

Citation: Wachholtz A, Bhowmick A, Herbert LB, Marcus D (2017) More is not Always Better: An Epidemiological Assessment of Migraine Frequency and the Impact on Relationships. J Pain Manage Med 3: 126

Copyright: (c) 2017 Wachholtz A, et al. This is an open-access article distributed under the terms of the Creative Commons Attribution License, which permits unrestricted use, distribution, and reproduction in any medium, provided the original author and source are credited. 
and approved by a local Institutional Review Board. Participants were informed about the voluntary nature of the survey, information being collected, anonymous nature of data collection, and the expected time for survey completion. No personal identifiers were collected or stored with the data.

\section{Recruitment}

Potential participants were recruited as a convenience sample to an English-language survey, with links posted on websites targeting migraine communities, including Migraine.com and the National Headache Foundation, and additional promotion through Facebook and Twitter. Adults with migraine were invited to participate in the survey if they were at least 18 years old, fluent in English, U.S.-based, and had previously received a diagnosis of migraine. No compensation was provided for participation.

Electronic data collection was conducted through SurveyMonkey, with data protected through their security measures. After reviewing information about the nature of the survey, participants were provided with an adaptive survey consisting of up to 47 multiplechoice questions and an optional open-ended response item. The survey required completion of each question prior to progressing to the next page of questions, which avoided missing data. Responses were collected without personal identifiers; however, participants' IP addresses were used to ensure the questionnaire was completed only once by any individual. Duplicate entries were avoided by preventing users with the same IP address from accessing to the survey more than once during the study period.

\section{Data collection}

The survey included demographic questions and questions about the effect of migraine on relationships with spouses/partners, children old enough to understand migraine, and close friends. Because some participants may have children who they might consider to be too young to understand or be aware of illness in a parent, participants were asked to answer questions only about their children whom they believed were old enough to understand migraine; no age cut-off was suggested. This same language was used in a previously conducted study [5]. The survey also included standardized assessment measures for migraine, anxiety, depression, and relationship satisfaction. After completing the mulitple-choice questions, participants were given the option of completing an open-ended response to share additional observations or concerns about how migraine may impact their relationships.

Migraine was confirmed using the three-item ID-migraine screener, which has been validated against clinical diagnosis using International Headache Society migraine criteria. ${ }^{14}$ Participants were asked about headaches over the last 3 months and asked questions about photophobia, nausea, and disability associated with headaches; migraine was identifed when at least two responses were positive. Mood disorders were screened for using the four-item, standardized, ultrabrief Patient Health Questionnaire (PHQ-4) that results in a PHQ-2 score for depression (possible range 0-6) and Generalized Anxiety Disorder (GAD)-2 for anxiety (possible range 0-6) [14,15]. Continuous data was leveraged for the PHQ-2 and GAD-2, using the recommended score cut-off of $\geq 3$ to identify potential depression and anxiety.

Participants were asked to react to a series of 4 relationship impact statements that were previously validated in a survey of relationship impact among adults with fibromyalgia [5]. The relationship impact statements addressed potential experiences with others in their lives questioning the veracity of their migraine symptoms, expressing concern that the migraineur exaggerated symptoms, accusing the migraineur of being lazy or selfish, and resenting when the migraineur was unable to participate in activities; statements were adapted for spouse/partner, children, and close friends. Participants provided responses to the relationship impact statements on a 5-point Likert scale from strongly disagree (1) to strongly agree (5). These scores were used to generate means within frequency groups. Overall current marital or partner relationship satisfaction was evaluated using the Relationship Assessment Scale (RAS), a seven-item questionnaire scoring from low (1) to high (5) satisfaction that has been previously validated in married and unmarried couples. ${ }^{16-18}$ Relationship satisfaction was identified as satisfied for participants scoring RAS $\geq 4$ and not satisfied for those with RAS $<4$. This cut-off has been previously used to identify relationship satisfaction [5].

\section{Data analysis}

Participant demographics and question responses were evaluated using descriptive statistics. Subjects were divided into migraine frequency categories by self-reported typical migraines per month: $0-3,4-9,10-15$, and $>15$. These categories were selected to identify individuals with infrequent migraine (less than weekly), lowmoderate frequency ( 1 migraine weekly), high-moderate frequency (two migraines weekly), and highly frequent migraine (more than two migraines weekly). Comparisons between categorical variables were evaluated using Chi-square analyses. Differences in mean Likert scores among migraine frequency categories were evaluated using an ANOVA with Bonferroni correction. Because comorbid psychological distress might influence relationship impact, a secondary analysis was performed on relationship impact questions among individuals with neither depression nor anxiety. Due to the computerized nature of the assessment, there was no missing data.

The optional open-ended response item was evaluated initially by identifying statements that offered new information from what had been gathered using the structured questionnaire. Responses were evaluated for common category themes, such as relationship areas not previously addressed and emotional effects. Once major themes were identified, responses were divided based on frequency categories and individual responses within each theme were listed. The most commonly cited responses were used to generate a common response table.

\section{Results}

The survey was started by 1,542 individuals. A total of 143 participants were excluded from the final sample due to: 12 were not at least 18 years old, 48 had not been diagnosed with migraine, and 83 did not complete the survey after completing the two screening questions. Migraine was reported as typically occurring 0-3 times per month for 215 participants (15.4\%), 4-9 times monthly for 440 (31.5\%), 10-15 times monthly for 286 (20.4\%), and $>15$ times monthly for 458 (32.7\%). The vast majority of patients satisfied ID-migraine criteria, with no differences among diagnosis percentage among frequency groups (95.8\% with 0-3 migraines monthly, $97.7 \%$ with $4-9$ migraines monthly, $98.3 \%$ with $10-15$ migraines monthly, and $97.6 \%$ with $>15$ migraines monthly). Demographics were generally similar among groups (Table 1). Depression and anxiety were significantly correlated with migraine frequency categories $(r=0.257$ and $r=0.149$ respectively, $\mathrm{P}<0.001)$.

Participants with more frequent migraines were more likely to report missing family or social activities with the past 3 months (Figure 1). Likewise participants with more frequent migraines were 


\begin{tabular}{|c|c|c|c|c|c|}
\hline \multirow{3}{*}{ Characteristic } & \multicolumn{5}{|c|}{ Migraine Days a Month } \\
\hline & All & 0 to 3 & 4 to 9 & 10 to 15 & $>15$ \\
\hline & $(n=1,399)$ & $(n=215)$ & $(n=440)$ & $(n=286)$ & $(n=458)$ \\
\hline \multicolumn{6}{|l|}{ Gender } \\
\hline Female & $1,316(94.1 \%)$ & $193(89.8 \%)$ & $421(95.7 \%)$ & $273(95.5 \%)$ & $429(93.7 \%)$ \\
\hline Male & $83(5.9 \%)$ & $22(10.2 \%)$ & $19(4.3 \%)$ & $13(4.5 \%)$ & $29(6.3 \%)$ \\
\hline \multicolumn{6}{|l|}{ Age in years } \\
\hline$\leq 21$ & $23(1.6 \%)$ & $5(2.3 \%)$ & $4(0.9 \%)$ & $7(2.4 \%)$ & $7(1.5 \%)$ \\
\hline 22 to 34 & $309(22.1 \%)$ & $48(22.3 \%)$ & $101(23.0 \%)$ & $63(22.0 \%)$ & $97(21.2 \%)$ \\
\hline 35 to 44 & $453(32.4 \%)$ & $79(36.4 \%)$ & $131(29.8 \%)$ & $83(29.0 \%)$ & $160(34.9 \%)$ \\
\hline 45 to 54 & $385(27.5 \%)$ & $54(25.1 \%)$ & $126(28.6 \%)$ & $82(28.7 \%)$ & $123(26.9 \%)$ \\
\hline 55 to 64 & $195(13.9 \%)$ & $24(11.2 \%)$ & $66(15.0 \%)$ & $40(14.0 \%)$ & $65(14.2 \%)$ \\
\hline$\geq 65$ & $34(2.4 \%)$ & $5(2.3 \%)$ & $12(2.7 \%)$ & $11(3.8 \%)$ & $6(1.3 \%)$ \\
\hline \multicolumn{6}{|l|}{ Marital status } \\
\hline Married & $847(60.5 \%)$ & $119(55.3 \%)$ & $268(60.9 \%)$ & $170(59.4 \%)$ & $290(63.3 \%)$ \\
\hline Single- in a committed relationship & $190(13.6 \%)$ & $42(19.5 \%)$ & $67(15.2 \%)$ & $35(12.2 \%)$ & $46(10.0 \%)$ \\
\hline Single-not in a committed relationship & $211(15.1 \%)$ & $36(16.7 \%)$ & $53(12.0 \%)$ & $52(18.2 \%)$ & $70(15.3 \%)$ \\
\hline Separated/Divorced & $142(10.2 \%)$ & $16(7.4 \%)$ & $50(11.4 \%)$ & $28(9.8 \%)$ & $48(10.5 \%)$ \\
\hline Widowed & $9(0.6 \%)$ & $2(0.9 \%)$ & $2(0.5 \%)$ & $1(0.3 \%)$ & $4(0.9 \%)$ \\
\hline \multicolumn{6}{|l|}{ Currently living with* } \\
\hline Spouse & $869(62.1 \%)$ & $124(57.7 \%)$ & $274(62.3 \%)$ & $176(61.5 \%)$ & $295(64.4 \%)$ \\
\hline Non-spouse adult partner & $112(8.0 \%)$ & $21(9.8 \%)$ & $43(9.8 \%)$ & $23(8.0 \%)$ & $25(5.5 \%)$ \\
\hline Children $\leq 12$ years old & $319(22.8 \%)$ & $51(23.7 \%)$ & $97(22.0 \%)$ & $59(20.6 \%)$ & $112(24.5 \%)$ \\
\hline Teenage children $13-18 \mathrm{y} / \mathrm{o}$ & $255(18.2 \%)$ & $44(20.5 \%)$ & $74(16.8 \%)$ & $44(15.4 \%)$ & $93(20.3 \%)$ \\
\hline Adult children & $154(11.0 \%)$ & $18(8.4 \%)$ & $55(12.5 \%)$ & $24(8.4 \%)$ & $57(12.4 \%)$ \\
\hline Others not listed above & $166(11.9 \%)$ & $27(12.6 \%)$ & $42(9.5 \%)$ & $36(12.6 \%)$ & $61(13.3 \%)$ \\
\hline Live alone & $206(14.7 \%)$ & $33(15.3 \%)$ & $63(14.3 \%)$ & $49(17.1 \%)$ & $61(13.3 \%)$ \\
\hline Met the ID-migraine criteria & $1,364(97.5 \%)$ & $206(95.8 \%)$ & $430(97.7 \%)$ & $281(98.3 \%)$ & 447 (97.6\%) \\
\hline Depressive PHQ-2 $\geq 3$ & $516(36.9 \%)$ & $41(19.1 \%)$ & $127(28.9 \%)$ & $106(37.1 \%)$ & $242(52.8 \%)$ \\
\hline Anxiety GAD-2 $\geq 3$ & $553(39.5 \%)$ & $56(26.0 \%)$ & $153(34.8 \%)$ & $108(37.8 \%)$ & $236(51.5 \%)$ \\
\hline
\end{tabular}

Table 1: Participant demographics, for all participants and each migraine frequency.

more likely to avoid making plans because they might get a migraine. Avoiding plans sometimes and often, respectively, were reported by $36.3 \%$ and $12.1 \%$ with $0-3$ migraines per month, $48.9 \%$ and $26.4 \%$ with 4-9 migraines per month, $37.4 \%$ and $47.2 \%$ with $10-15$ migraines per month, and $21.0 \%$ and $70.7 \%$ with $>15$ migraines per month.

\section{Relationship impact}

Participants with more frequent migraine were more likely to report migraines had negatively impacted a relationship(s) with spouse(s)/partner(s) (Figure 2). When asked about relationships with their current spouse or partner, however, satisfaction was similar among groups. Most participants reported their current spouse/ partner understood their migraine impact, although those with more frequent migraines viewed this as a burden on the spouse/partner (Table 2). Mean RAS scores were similar among the migraine frequency categories: $4.0 \pm 0.9$ for participants with $0-3$ migraines monthly, 3.9 \pm 0.9 for $4-9$ migraines, $3.9 \pm 0.9$ for $10-15$ migraines, and $3.9 \pm 0.9$ for $>15$ migraines. RAS scores identified satisfaction with a current partner/spouse for $57.8 \%$ with $0-3$ migraines monthly, $58.6 \%$ with $4-9$ migraines, $56.2 \%$ with $10-15$ migraines, and $54.7 \%$ with $>15$ migraines. In addition, relationship satisfaction based on RAS cut-off was not affected by marital status ( $57.5 \%$ satisfied among married participants and $57.9 \%$ among single participants in a relationship with a partner). As anticipated, depression was negatively correlated with RAS scores $(\mathrm{r}=-0.220, \mathrm{P}<0.001)$, as well as anxiety $(\mathrm{r}=-0.150, \mathrm{P}<0.001)$.

Comparisons among frequency groups for impact of migraines on relationships with spouse/partner, children, and close friends showed more impact with increased frequency, with the least impact of frequency on relationship with spouse/partner (Table 3). As migraine frequency increased, close friends were more likely to question whether migraine was real. Both children and close friends were perceived as being more likely to view migraine pain as exaggerated as migraine frequency increased. For all groups, perceptions of being viewed as lazy/selfish and being resented for not being able to participate in activities increased with migraine frequency. In order to assess the unique relationship between migraines and relationship impact without the influence of mental health disorders, analyses utilizing only participants who were neither depressed nor anxious likewise showed some significant differences among frequency categories. Higher negative impact correlated with increased migraine frequency for perceptions that children and close friends believe pain is exaggerated $(\mathrm{r}=0.111, \mathrm{P}<0.02)$. And that children resent time missed from activities due to migraine $(\mathrm{r}=0.120, \mathrm{P}<0.017)$.

\section{Open-ended response}

The open-ended response item was answered by 712 participants. Major themes included emotional impact from migraines, overall life impact, relationship impacts not addressed by survey questions, and work impact. A summary of the most frequently encountered responses within each migraine frequency category are listed in Table 4. In general, distress, isolation, and hopelessness increased with increasing migraine frequency. People with infrequent migraines talked about others around them understanding their migraines and migraine impact and those with moderate frequency migraine talked about their feelings of guilt from missing out on time with their loved ones. Individuals with $>15$ migraines per month viewed discussing migraines with others as often counterproductive and frequently reported a lack of expectation that others might be able to understand. 
Citation: Wachholtz A, Bhowmick A, Herbert LB, Marcus D (2017) More is not Always Better: An Epidemiological Assessment of Migraine Frequency and the Impact on Relationships. J Pain Manage Med 3: 126

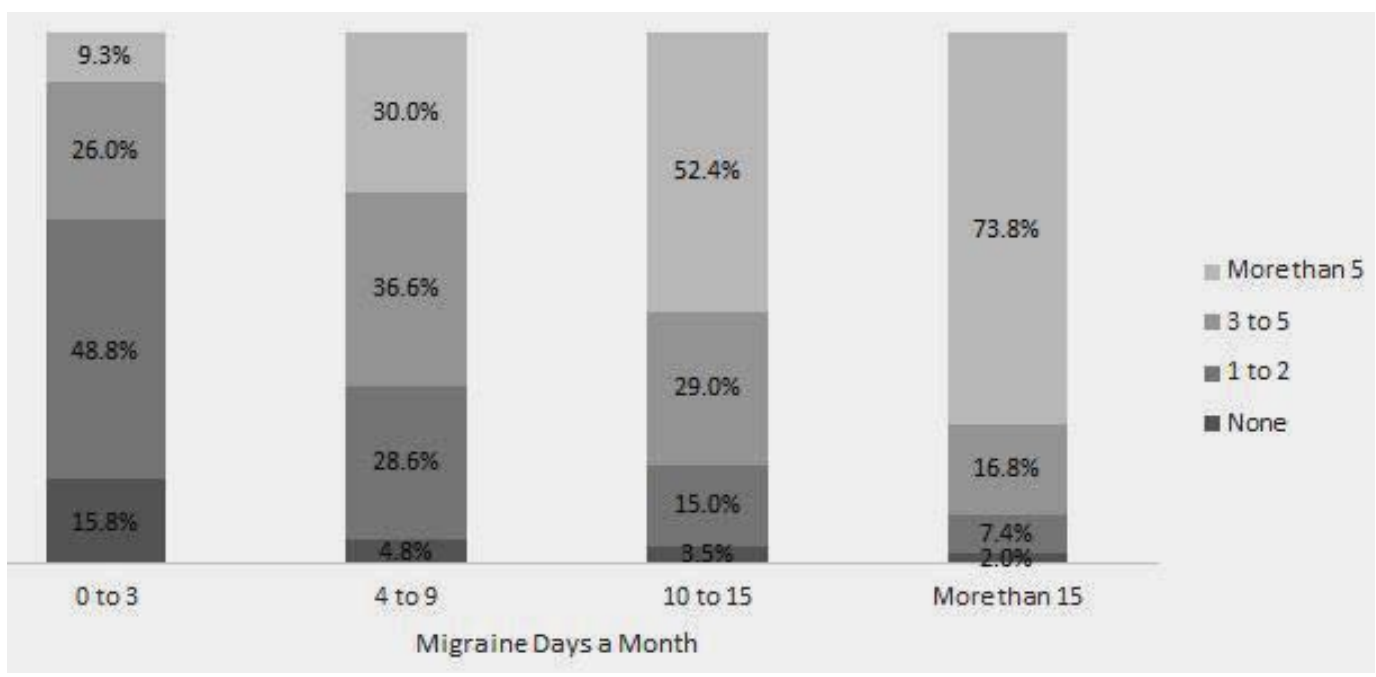

Figure 1: Number of days missing family or social activities during the preceding 3 months due to migraine $(1,399)$.

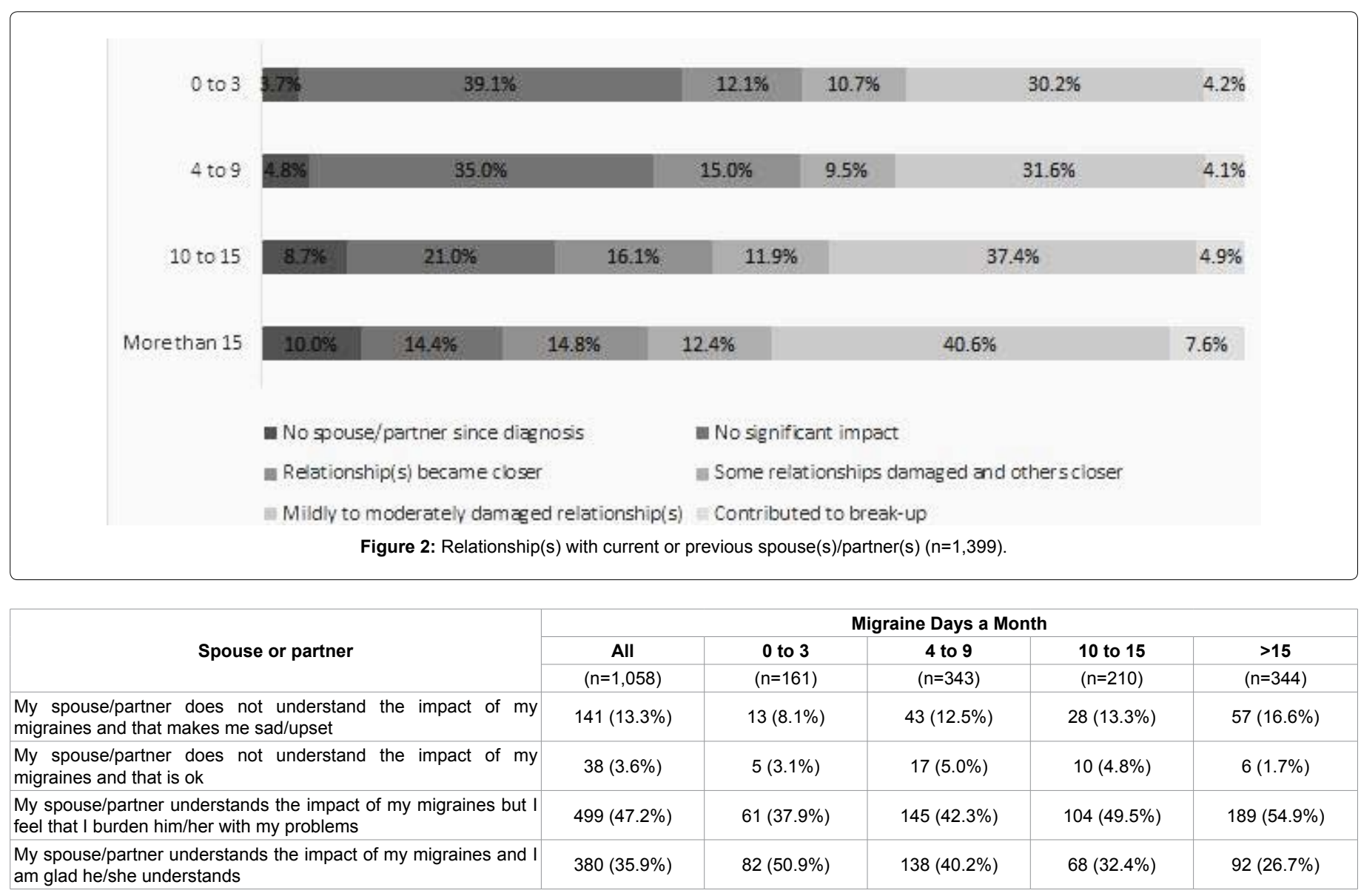

Table 2: Spouse or partner's understanding of migraine impact. 


\begin{tabular}{|c|c|c|c|c|c|}
\hline \multirow{3}{*}{ Spouse or partner } & \multicolumn{5}{|c|}{ Migraine Days a Month } \\
\hline & All & 0 to 3 & 4 to 9 & 10 to 15 & $>15$ \\
\hline & $(n=1,058)$ & $(n=161)$ & $(n=343)$ & $(n=210)$ & $(n=344)$ \\
\hline Questions whether migraine is a real physical illness & $12.70 \%$ & $10.60 \%$ & $12.50 \%$ & $10.50 \%$ & $15.10 \%$ \\
\hline Thinks I exaggerate my migraine pain & $16.70 \%$ & $12.40 \%$ & $15.50 \%$ & $19.00 \%$ & $18.60 \%$ \\
\hline Accuses me of being lazy or selfish because of my migraines & $14.50 \%$ & $6.80 \%$ & $11.40 \%$ & $14.30 \%$ & $21.20 \%$ \\
\hline Resents I am unable to do things with them because of my migraines & $29.60 \%$ & $24.20 \%$ & $24.20 \%$ & $30.00 \%$ & $37.20 \%$ \\
\hline \multirow{2}{*}{ Children } & All & 0 to 3 & 4 to 9 & 10 to 15 & $>15$ \\
\hline & $(n=788)$ & $(n=108)$ & $(n=252)$ & $(n=163)$ & $(n=265)$ \\
\hline Questions whether migraine is a real physical illness & $12.80 \%$ & $5.60 \%$ & $11.90 \%$ & $16.60 \%$ & $14.30 \%$ \\
\hline Thinks I exaggerate my migraine pain & $12.30 \%$ & $2.80 \%$ & $11.10 \%$ & $14.70 \%$ & $15.80 \%$ \\
\hline Accuses me of being lazy or selfish because of my migraines & $12.20 \%$ & $3.70 \%$ & $10.70 \%$ & $14.10 \%$ & $15.80 \%$ \\
\hline Resents I am unable to do things with them because of my migraines & $33.50 \%$ & $19.40 \%$ & $28.60 \%$ & $38.00 \%$ & $41.10 \%$ \\
\hline \multirow{2}{*}{ Friends } & All & 0 to 3 & 4 to 9 & 10 to 15 & $>15$ \\
\hline & $(n=1,112)$ & $(n=184)$ & $(n=357)$ & $(n=224)$ & $(n=347)$ \\
\hline Questions whether migraine is a real physical illness & $14.70 \%$ & $9.20 \%$ & $12.00 \%$ & $17.40 \%$ & $18.70 \%$ \\
\hline Thinks I exaggerate my migraine pain & $16.20 \%$ & $10.30 \%$ & $14.00 \%$ & $19.20 \%$ & $19.60 \%$ \\
\hline Accuses me of being lazy or selfish because of my migraines & $8.60 \%$ & $4.30 \%$ & $7.30 \%$ & $10.30 \%$ & $11.20 \%$ \\
\hline Resents I am unable to do things with them because of my migraines & $22.70 \%$ & $15.20 \%$ & $18.50 \%$ & $25.40 \%$ & $29.10 \%$ \\
\hline
\end{tabular}

Table 3: Relationship perceptions by migraine frequency.

\begin{tabular}{|c|c|}
\hline Migraine Days a Month & Remarks \\
\hline 0 to 3 & Others are understanding and supportive when missing events \\
\hline \multirow{3}{*}{$(n=80)$} & Fear of the potential future impact on their current relationships \\
\hline & Blame themselves when missing an occasion or work \\
\hline & Will avoid situations known to bring on a migraine or aura \\
\hline 4 to 9 & Despite others being supportive, there is a strong sense of guilt over canceling plans or missing time with friends and family \\
\hline \multirow[t]{3}{*}{$(n=213)$} & It is difficult to explain migraines to their children \\
\hline & Employers and co-workers do not understand the debilitating effect \\
\hline & Hesitant to make social plans or start a new romantic relationship \\
\hline 10 to 15 & Find themselves unable to make social plans or cancelling plans too often, leading to loneliness and sadness \\
\hline \multirow[t]{2}{*}{$(n=155)$} & Co-worker perceptions are harder to deal with than those of loved ones, with migraines resulting in loss of employment for some \\
\hline & Have lost friends over the years due to the impact of migraine \\
\hline$>15$ & Migraines are disabling, being attributed as "ruining" one's social life, family relationships, and their career \\
\hline \multirow{3}{*}{$(n=264)$} & Family, friends, and co-workers are often not understanding and will not take time to fully comprehend migraines \\
\hline & With triggers so prevalent in social situations, individuals are limited in what they can do or where they can go \\
\hline & Migraines impact physical and emotional relationships, often resulting in them ceasing as well as new ones not developing \\
\hline
\end{tabular}

Table 4: Common themes addressed by participants completing the open-ended response question, by migraine frequency.

\section{Discussion}

Migraine frequency was linked with relationship impact. As migraine frequency increased, negative impact on relationships also increased. Interestingly, satisfaction with current spouse/partner was high for all migraine frequency categories. As migraine frequency increased, psychological distress was also increased. Comorbid psychological distress was an important factor influencing negative relationship impact, although some negative impacts on relationships with children and close friends were significantly greater as migraine frequency increased, even among individuals without depression or anxiety.

Marital satisfaction in the current study is consistent with the previous report in a mixed group of chronic pain patients, which reported dissatisfaction in $39 \%$ [1]. In that sample, $40 \%$ of patients had low back pain/sciatica, $25 \%$ had a headache diagnosis, $17 \%$ had neurogenic pain. The current sample defined spouse/partner satisfaction using a different measurement tool, however, results were not markedly dissimilar to those for the mixed pain population. Results from this study support previously published studies in chronic pain populations linking depression and anxiety with reduced spouse/ partner relationship satisfaction [2,6,7,16-19]. Open-ended responses identified a tendency of participants with higher migraine frequency to reduce discussions about migraine, with participants less likely to report benefit from sharing issues with others when migraine frequency was higher. This supports a previously published study in which 95 adults with chronic pain and their spouses were surveyed. In that study, increasing patients' disclosures about pain was associated with erosion of spousal support and an increase in invalidating responses to the patient [20].

Pain frequency in migraine may be a correlate of pain severity for other types of chronic pain. In migraine, the diagnosis includes a severity rating of moderate to severe. Participants in the American Migraine Prevalence and Prevention (AMPP) study were asked to rate their most recent long duration migraine, with individuals identified as having more substantial migraine -related disability reporting only slightly higher pain severity scores than those with little or no migrainerelated disability (8.1 vs. 7.4) [21]. A separate analysis from AMPP data reported average headache pain severity of 7.6 for individuals with episodes occurring $<15$ days per month and 7.8 for those with headaches $\geq 15$ days per month [22]. Migraine episodes may include other potentially disabling features (e.g., photophobia, phonophobia, and nausea) that might not be included in pain severity ratings. In addition, pain severity often fluctuates among individual migraine 
episodes, making determination of an average migraine pain severity rating challenging.

Interpreting data from this study is limited by several factors. Although participants were asked about migraine frequency, comorbid mood symptoms, and relationship issues, the associations identified do not confirm a causal relationship. In addition, there may have been other confounding factors, such as typical migraine duration, maximum pain severity, or severity of associated symptoms that might be important confounding factors. The predominance of females $\geq 35$ years old in the current sample is similar to previous samples obtained through online surveys for migraine; [11-13,23,24], however, data may not be generalized to males or younger females with migraine. In addition, utilization a convenience online sample has potential inherent biases that may limit generalization to random community or patient samples. Individuals visiting migraine community websites and social media and opting to participate in a survey are not necessarily representative of community migraineurs in general. Data were not collected on the number of unique individuals who might have viewed websites and social media promoting the survey to know the proportion of those aware of the survey who opted to participate. In addition, previous research showed that individuals with $>15$ migraines monthly were more likely to utilize web-based resources [12]. Although not specifically addressed in that study, these individuals might also be more likely to participate in online surveys, potentially skewing the study population. In addition, similar to previously published data from the AMPP, mood disorder prevalence increased in the current study with migraine frequency [25]. Overall, however, prevalence of anxiety and depression were higher in our sample than the AMPP study, in which anxiety and depression, respectively, occurred for $19 \%$ and $17 \%$ with migraines occurring $<15$ days per month and $30 \%$ for both among individuals with headaches $\geq 15$ days per month. In our online sample, anxiety prevalence ranged from $19 \%$ among those with 0-3 migraines monthly to $53 \%$ for those with $>15$ migraines monthly. Depression ranged from $26 \%$ with $0-3$ migraine monthly to $52 \%$ with $>15$ migraines monthly. These data suggest that psychological distress was higher among the current sample than might be anticipated in a general community sample with migraine. In addition, participants were not given a suggestion for the age at which a child might be expected to be able to understand a parent's pain problem. Participants were allowed to self-determine if they expected their child should be old enough to understand or not; therefore, some individuals likely excluded younger children who might have been included by a different participant.

In summary, the current study showed that increasing migraine frequency was linked with mood disturbance and negative impact on relationships for this migraine sample. These data support screening for mood disturbances and investigating possible relationship impacts among migraineurs with more frequent migraine. While migraine frequency was adversely linked with relationship impact in the current study, additional research is needed to determine if patients with other types of chronic pain may experience greater interference as their number of pain flares increases.

\section{Clinical Implications}

- Frequent migraineurs should be screened frequently for negative mood.

- Frequent migraines may adversely affect the quality of the patient's relationships.

- Frequent migraineurs experiencing social isolation or social conflict may benefit from a referral to individuals or couples therapy.

\section{Conflict of Interest}

Amy Wachholtz has no conflicts to declare. Amrita Bhowmick and LB Herbert declare this study was completed using a commercial website for a for-profit company. Amrita Bhowmick and LB Herbert are employees of Health Union, LLC, and the proprietor of the website but receive no financial incentive related to the publication of this manuscript. Dawn Marcus has no conflicts of interest to declare.

\section{Acknowledgement}

Amy Wachholtz's effort on this project was funded by NIH-NIDA Grant\#K23DA030397.

\section{References}

1. Flor H, Turk DC, Scholz OB (1987) Impact of chronic pain on the spouse: Marital, emotional and physical consequences. J Psychosom Res 31: 63-71.

2. Leonard MT, Cano A (2006) Pain affects spouses too: Personal experience with pain and catastrophizing as correlates of spouse distress. Pain 126: 139-146.

3. Waxman SE, Tripp DA, Flamenbaum R (2008) The mediating role of depression and negative partner responses in chronic low back pain and relationship satisfaction. J Pain 9: 434-442.

4. Geisser ME, Cano A, Leonard MT (2005) Factors associated with marital satisfaction and mood among spouses of persons with chronic back pain. $J$ Pain 6: 518-525.

5. Marcus DA, Richards KL, Chambers JF, Bhowmick A (2013) Fibromyalgia family and relationship impact exploratory survey. Musculoskeletal Care 11: 125-134.

6. Cano A, Johansen AB, Leonard MT, Hanawalt JG (2005) What are the marita problems of patients with chronic pain? Curr Pain Headache Rep 9: 96-100.

7. Leonard MT, Cano A, Johansen AB (2006) Chronic pain in a couples context $A$ review and integration of theoretical models and empirical evidence. J Pain 7: 337-390.

8. Lipton RB, Bigal ME, Kolodner K Stewart WF, Liberman JN, et al. (2003) The family impact of migraine: population-based studies in the USA and UK. Cephalalgia 23: 429-440.

9. Dueland AN, Leira R, Burke TA, Hillyer EV, Bolge S (2004) The impact of migraine on work, family, and leisure among young women --a multinational study. Curr Med Res Opin 20: 1595-1604.

10. Oppenheimer AJ, Pannucci CJ, Kasten SJ, Haase SC (2011) Survey says? A primer on web-based survey design and distribution. Plast Reconstr Surg 128: 299-304.

11. MacGregor EA, Brandes J, Eikermann A, Giammarco R (2004) Impact of migraine on patients and their families: The Migraine and Zolmitriptan Evaluation (MAZE) survey -- Phase III. Curr Med Res Opin 20: 1143-1150.

12. Marcus DA, Bhowmick A (2013) Migraine frequency but not self-efficacy drives utilization and impact from online resources. Headache 53: 551-552.

13. Marcus DA Bhomick A (2013) Survey of migraine sufferers with dogs to evaluate for canine migraine-alerting behaviors. J Altern Complement Med 19 501-508.

14. Lipton RB, Dodick D, Sadovsky R, Kolodner K, Endicott J, et al. (2003) A selfadministered screener for migraine in primary care: The ID Migraine validation study. Neurology 61: 375-382.

15. Kroenke K, Spitzer RL, Williams JW, Löwe B (2009) An ultra-brief screening scale for anxiety and depression: The PHQ-4. Psychosomatics 50: 613-621.

16. Hendrick SS (1988) A generic measure of relationship satisfaction. J Marriage Fam 50: 93-98.

17. Hendrick SS, Dicke A, Hendrick C (1998) The relationship assessment scale. J Soc Pers Relat 15:137-142.

18. Vaughn MJ, Baier MM (1999) Reliability and validity of the relationship assessment scale. Am J Fam Ther 27:137-147. 
Citation: Wachholtz A, Bhowmick A, Herbert LB, Marcus D (2017) More is not Always Better: An Epidemiological Assessment of Migraine Frequency and the Impact on Relationships. J Pain Manage Med 3: 126

Page 7 of 7

19. Malone CD, Bhowmick A, Wachholtz AB (2015) Migraine: Treatments, comorbidities, and quality of life in the USA. J of Pain Res 8: 537-547.

20. Cano A, Leong LE, Williams AM, May DK, Lutz JR (2012) Correlates and consequences of the disclosure of pain-related distress to one's spouse. Pain 153: $2441-2447$

21. Lipton RB, Serrano D, Holland S, Fanning KM, Reed ML, et al. (2013) Barriers to the diagnosis and treatment of migraine: Effects of sex, income, and headache features. Headache 53: 81-92.

22. Buse D, Manack A, Serrano D, Reed M, Varon S, et al. (2012) Headache impact of chronic and episodic migraine: Results from the American Migraine Prevalence and Prevention study. Headache 52: 3-17.
23. Blumenfeld AM, Varon SF, Wilcox TK, Buse DC, Kawata AK, et al. (2011) Disability, RRQoL and resource use among chronic and episodic migraineurs: Results from the International Burden of Migraine Study (IBMS). Cephalalgia 31: 301-315.

24. Landy SH, Runken MC, Bell CF, Higbie RL, Haskins LS (2012) Examining the interrelationship of migraine onset, duration, and time to treatment. Headache 52: 363-373.

25. Buse DC, Manack A, Serrano D, Turkel C, Lipton RB (2010) Sociodemographic and comorbidity profiles of chronic migraine and episodic migraine sufferers. $J$ Neurol Neurosurg Psychiatry 81: 428-432. 